\title{
A Saúde Mental e a Fabricação da Normalidade: Uma Crítica aos Excessos do Ideal Normalizador a Partir das Obras de Foucault e Canguilhem
}

\author{
Magali Milene Silva \\ Universidade Federal de Minas Gerais
}

\begin{abstract}
RESUMO
Através da revisão das discussões levantadas por Georges Canguilhem e Michel Foucault, pretende-se caracterizar a construção conceitual de "doença mental" como intrinsecamente relacionada às normas sociais. O conceito de "doença" refere-se a um julgamento socialmente embasado a respeito de certas manifestações, estabelecendo-as como inadequadas. Na medicina, a biologia (o dado químico ou fisiológico) serve de parâmetro para julgar uma diferença como doença. No campo da saúde mental, por outro lado, os parâmetros para a definição do patológico encontram dificuldades em apoiar-se na biologia, situando-se claramente no campo dos valores. A doença mental, correlato de anormalidade, é concebida em relação às normas sociais, sendo, por isso, aplicável aos sujeitos que não se submetem adequadamente a elas. Nesse sentido, a função dos tratamentos mentais seria a normalização dos indivíduos, fixando-os às normas de que se distanciaram. Através da reflexão ética, entretanto, é possível que a saúde mental encontre um outro patamar que ultrapasse a adaptação social, permitindo a expressão da diferença e da criatividade.
\end{abstract}

Palavras-chave: saúde mental; normalização; tratamento mental; diferença.

\section{ABSTRACT \\ Mental Health and the Manufacture of Normality: A Criticism to the Excesses of the Normalcy Ideal from Foucault and Canguilhem's Work}

Revising the discussions made by Georges Canguilhem and Michel Foucault, this study was intended to characterize the conceptual construction of "mental illness" as fully related to social rules. The concept of "illness" involves a socially based judgment about some manifestations which establishes them as inadequate. Often in Medicine, biological data (chemical or physiological), is used to judge difference as illness. In Mental Health, on the other hand, the rules used to define the pathological cannot be supported by biological data - they are clearly situated in the field of values. Mental illness, correlated to abnormality, is defined according to the social rules, and these concepts are applied to those who do not submit to these rules. In this sense, the goal of mental treatments would be the normalization of individuals, adapting them to these rules. Through ethical reflection however, it is possible for the field of Mental Health to go beyond social adaptation, making possible the expression of difference and creativity.

Keywords: mental health; normalization; mental treatment; difference.

Sem a loucura que é o homem

Mais que a besta sadia,

Cadáver adiado que procria?

Fernando Pessoa (1976)

Presenciamos atualmente uma grande atenção da sociedade às patologias psíquicas. No Ocidente do século XXI, as doenças nervosas, munidas de um aparato científico que as define e justifica, assumem um destacado lugar no interesse da mídia e, conseqüentemente, na atenção popular. Mas, o que é uma patologia psíquica - doença mental, transtorno psicológico ou qualquer outro nome que designe em menor ou maior grau o que outrora chamamos simplesmente de loucura?

A definição de doença mental é o primeiro problema que se apresenta às propostas de tratamento psicológico, uma vez que uma proposta de tratamento parte do que se entende por uma doença. Sendo sim- 
plistas, podemos dizer que se uma patologia é uma disfunção química, o tratamento deve ser farmacológico; por outro lado, se uma patologia se refere à dificuldade de adaptação social, o tratamento deve ser o treinamento adaptativo e assim por diante. O diagnóstico, simplesmente, não responde à questão do que é uma patologia, ele apenas estabelece, a partir de critérios legitimados por um discurso específico, a inserção de determinadas manifestações em tipologias de forma a orientar uma atuação. $\mathrm{O}$ que interessa em um diagnóstico é a validade dos critérios que conduzem a ele. A querela diagnóstica, grosso modo, pode ser resumida a uma disputa quanto à legitimação dos critérios que sustentam a classificação patológica e, conseqüentemente, a ação terapêutica.

Percorrendo a história da psiquiatria e da psicologia, percebemos a dificuldade no estabelecimento da doença mental e do tratamento mais adequado. Michel Foucault (2005a) defende a tese de que o conceito de loucura muda de acordo com mudanças ocorridas na sociedade que legitima esse conceito. Dito de outro modo, a legitimação de uma intervenção em saúde mental depende do conjunto de valores que prevalecem na sociedade naquele momento. Se uma definição de loucura é situada no tempo e no espaço, como garantir que os critérios adotados para gerar essa definição são melhores que outros quaisquer?

A psiquiatria e a psicologia, no curso de sua breve história, tentam estabelecer uma garantia para os critérios adotados, construindo um discurso que os fundamenta. Podemos, inclusive, situar nesse ponto a diferença entre as diversas concepções teóricas da psicologia e da psiquiatria, uma vez que o tratamento que propõem depende dos conceitos de doença e saúde que o orientam, e em última instância, dos critérios utilizados na construção desses conceitos. Seguindo na esteira de Georges Canguilhem $(1999,2002)$ e Michel Foucault (2000, 2001, 2002, 2003, 2005a,b) este estudo considera o estabelecimento de tais critérios como essencialmente valorativo, visto que sua aplicabilidade e permanência dependem da legitimação social, ou, em termos foucaultianos, do poder atribuído ao discurso que os constroem.

Primeiramente, as noções de saúde e doença são apresentadas como construções conceituais essencialmente valorativas, conforme teorizado por Canguilhem (2002). Em seguida, propõe-se uma discussão do lugar ético ocupado pelas diversas vertentes da saúde mental, considerando como referência as críticas efetuadas por Foucault $(2000,2001,2002,2003$, $2005 \mathrm{a}, \mathrm{b})$ em seus estudos sobre o poder na sociedade disciplinar. A partir dessas considerações, este artigo pretende efetuar uma crítica das "práticas psi", questionando sua possível implicação como participante de um processo de normalização acorde ao poder dominante. Nosso objetivo é levantar discussões que permitam repensar as implicações éticas da atuação dos profissionais $p s i$.

\section{A construção do conceito de doença}

Para Georges Canguilhem (2002), doença é uma construção valorativa. É um conceito construído a partir de uma articulação de pensamento, articulação esta justificada por valores. Uma definição de doença possui sempre um caráter qualitativo, uma vez que é um arbítrio sobre uma apresentação biológica, considerando-a inadequada em comparação àquilo que se considera o adequado - a saúde; isso quer dizer que a norma em relação a qual é possível caracterizar uma doença não é natural, mas construída de acordo com determinados valores. Na biologia, a forma nova ou diferente (não-habitual), como no caso das mutações, não é necessariamente negativa, uma vez que pode significar uma evolução no sentido de garantir a vida. Quando analisado sob o ponto de vista da oposição saúde versus doença, o patológico não é apenas um desvio da norma, mas uma norma diferente, valorizada como inferior. Portanto, um objeto só pode se tornar norma a partir de uma decisão que o insira numa hierarquia de valores, de modo que a norma não é natural, ela é produzida. A medicina estaria, portanto, situada no campo dos valores, embora utilizando o trabalho científico. Através de uma operação de valor, a medicina converte os conceitos descritivos em ideais normativos que irão orientar a terapêutica. A fisiologia define constantes funcionais que são classificadas como normais devido à sua freqüência estatística, mas que também são consideradas normais enquanto ideais de uma terapêutica.

A média e a moda estatísticas não podem conferir identidade à norma em que se baseia a medicina porque são expressões puramente descritivas. Podemos, por exemplo, ter apresentações que se encontram dentro da curva normal de um grupo e não são consideradas saudáveis, como cáries dentárias e episódios de gripe. Assim como ocorrências que não se encontram dentro das margens delimitadas pela curva normal e não são consideradas patológicas, como a capacidade física elevada dos atletas. Podemos dizer que embora a estatística das apresentações biológicas forneça um critério objetivo sobre o qual a medicina opera, ainda assim é preciso considerar a doença 
como instituição de um valor. Não é qualquer diferença em relação à freqüência estatística que caracterizaria o patológico, mas apenas uma diferença negativamente valorizada. É preciso deixar claro, então, que no campo da medicina, o termo anormal é essencialmente valorativo porque não diz respeito apenas a uma diferença, mas a uma diferença ruim.

Segundo Canguilhem (2002), esse julgamento não cabe ao médico, mas à própria vida que é em si atividade valorativa, tendendo a valorizar negativamente aquilo que constitui um impedimento ou impossibilidade para a sua conservação. Se a própria vida é um valor para o vivente que visa a sua manutenção, a medicina seria apenas um prolongamento desse valor. Canguilhem lança mão do termo normativo para descrever a capacidade do ser vivo de determinar normas de funcionamento que lhe permitam continuar vivo, a normatividade biológica seria, pois, o conjunto de atividades do organismo que o mantêm vivo. Podem existir, entretanto, normas que garantem melhor a continuidade da vida individual. Podemos considerar, então, o conceito de normatividade como capacidade de um indivíduo de estabelecer normas, de organizarse em sua relação com o meio; e o conceito de normalidade como julgamento a respeito da adequação a uma norma de funcionamento eleita como melhor. Normalidade para a medicina envolve, portanto, o estabelecimento de normas conformes a um valor, pressupondo a hierarquização das possibilidades normativas, elegendo a melhor, a qual o vivente deve adequar-se. Todo ser vivo apresenta uma normatividade vital, uma capacidade de organizar-se na interação com o meio e que o permite viver. Há, contudo, normas que permitem melhores possibilidades adaptativas. Para Canguilhem, é o próprio indivíduo que deve ser o ponto de partida para o julgamento da doença, já que a vida é o valor fundamental. Nesse sentido, o patológico seria uma normatividade inferior, que acarretasse ao indivíduo menor possibilidade de manter a vida, ou que restringisse as possibilidades adaptativas, diminuindo a capacidade individual de relacionar-se com o meio. Curar, nessa perspectiva, seria expandir a normatividade individual restringida pela doença. O tratamento, baseado na singularidade, teria como ponto de ancoragem a satisfação subjetiva da ampliação da normatividade. Saúde implicaria capacidade de reação às intempéries da vida: "estar em boa saúde é poder cair doente e se recuperar; é um luxo biológico" (Canguilhem, 2002, p. 160).

Podemos inferir que a noção de saúde apresentada por Canguilhem é próxima à idéia de maleabilidade.
Saúde seria uma variação no jogo das normas de forma a estabelecer uma relação com o meio que possibilite a vida, o que permite definir doença como incapacidade adaptativa ou a perda da plasticidade. Uma diferença biológica em si não caracterizaria uma doença porque a variação é condição de possibilidade da vida. Nessa perspectiva, a saúde só pode ser entendida em sua relação direta com a doença, em sua possibilidade de criação e, por conseguinte, de risco inerente à vida. Estar vivo apenas não é estar saudável. A manutenção do organismo não é o único critério para a saúde, é preciso que o indivíduo esteja em condições de relacionar-se normativamente com o meio, ou seja, de criar valor, de instaurar normas vitais. Essa definição supõe certa adaptação, porém ultrapassa o adaptável. Não é apenas capacidade de adaptar-se ao meio, mas também capacidade de constituir novas formas em situações novas. Para Canguilhem (2002), a cura é a reconquista de um estado individual estável de relação com o meio, mas, logicamente, passível de modificações.

\section{Doença e normalidade}

O texto de Canguilhem é claro na demonstração de sua hipótese fundamental: qualquer norma que vise a delimitar a patologia tem um fundamento moral: "Não há uma ciência biológica do normal. Há uma ciência das situações e das condições biológicas consideradas normais" (Canguilhem, 2002, p. 188). Para este autor, no entanto, admitir o caráter não natural da patologia não põe fim à discussão. Se por um lado, é preciso reconhecer a arbitrariedade de qualquer definição do patológico, por outro, a vida não pode prescindir dela porque a vida é em si um valor. Ele não se furta a propor uma outra possibilidade de condução da relação entre saúde e doença que não a delimitação linear de características que separem os campos do normal e do patológico. Sua argumentação, entretanto, não nos permite esquecer que a medicina é moral, uma vez que sua atividade fundamental é estabelecer valores em relação aos quais a saúde e a doença serão discriminadas.

A média se aplica a um espaço num determinado momento. Ela descreve, em fisiologia, constantes funcionais, que podem, no entanto, variar, dada a maleabilidade humana, individual e coletiva: "considerar os valores médios das constantes fisiológicas humanas como a expressão de normas coletivas de vida seria apenas dizer que a espécie humana, inventando gêneros de vida inventa, ao mesmo tempo, modos de ser fisiológicos" (Canguilhem, 2002, p. 139). Através da 
norma, a sociedade visa a unificar o diverso, moldando as diferenças: uma norma fixa possibilidades. A operação social de normalização, de escolha de uma norma de vida como a melhor para os indivíduos na sociedade, estabelece, a partir de uma hierarquia de valores, um conjunto de expressões possíveis para a individualidade. Ora, uma sociedade que funcione a partir da idéia de normalização utilizar-se-á de instituições que exerçam essa função, conforme será amplamente discutido por Foucault $(2005 \mathrm{a}, 2005 \mathrm{~b})$ a propósito da sociedade disciplinar.

Apesar da dificuldade concernente ao estabelecimento de normas para vida, a medicina não cessa de apresentar possibilidades de delimitação, pois é esse, exatamente, o seu campo de trabalho. Em O Nascimento da Clínica (2003), Foucault descreve as mudanças que ocorreram na clínica médica a partir do momento em que ela começa a se tornar objetiva, em que caberá ao médico traduzir a linguagem do corpo dos órgãos, dos tecidos, da bioquímica - para classificar a doença, momento em que os dados fisiológicos objetivamente percebidos servirão de orientação para a atuação clínica. Em tal operação clínica, o olhar deve revelar, ou melhor, traduzir, a verdade dos órgãos. A essa medicina interessa não apenas a cura das doenças, mas a delimitação do homem saudável, do homem modelo, cuja função do Estado é produzir. Como conseqüência, "na gestão da existência humana, toma uma postura normalizante, que não a autoriza apenas a distribuir conselhos da vida equilibrada, mas a reger as relações físicas e morais do indivíduo e da sociedade em que vive" (Foucault, 2003, p. 39).

O olhar da clínica anatômica deve traduzir a verdade do organismo, falar a língua dos órgãos. É a natureza que fala e o médico deve ser o seu tradutor. Ao médico, cabe atribuir valor ao observado não apenas descrevendo, mas comparando o que é com o que deveria ser. Ora, se são as coisas ou a natureza que revela sua verdade ao olhar sábio e instrumentalizado, se a verdade é, portanto, objetiva, é possível não apenas descrever, mas contar e enumerar as doenças. Estamos diante da crença de que o olhar médico atingiu um domínio de clara visibilidade: o domínio dos fatos científicos. Esse olhar pode ser julgado puro porque se faz pelo silêncio da teoria: não é mais uma construção nosográfica que o orienta, mas a contabilidade das coisas. O objetivo é a "passagem, sem resíduo, da totalidade do visível à estrutura do conjunto enunciável" (Foucault, 2003, p. 129), olhar pleno, pois escuta a fala das coisas e a transmite.
A descrição anatômica, a partir do estudo de cadáveres, permite ao corpo revelar sua verdade em unidades cada vez menores, até que a coisa que fala a verdade da patologia seja a química e o olhar clínico se torne microscópico. Novas classificações surgem claramente baseadas em descrições científicas do corpo. Quando a clínica passa por essa mudança, haverá, para a medicina, um ponto fixo - o fisiológico, e uma variante mais ou menos rígida porque influenciada pela individualidade - a sintomatologia.

Essa pequena incursão pela medicina através das obras de Canguilhem e Foucault objetivou demonstrar que doença é um conceito construído a partir de um conjunto de critérios orientados por um valor. Na medicina, a vida humana é o valor máximo e, atualmente, o dado fisiológico ou químico, objetivamente medido, o critério essencial. Não devemos desconsiderar o fato de que hoje em dia a sociedade e a própria medicina se questionam se a vida deve ser o valor máximo, ou apenas a vida em determinadas condições, donde as discussões a respeito da eutanásia. Tampouco podemos ignorar as controvérsias referentes à busca de descrições exatas da bioquímica e da fisiologia e ao desenvolvimento de medicamentos. No entanto, para além dessas especificidades e dificuldades, importou destacar as proposições que permitem à medicina se constituir, operando a partir do conceito de doença, o que ajudará a pensar como o conceito de doença mental foi/é construído pelas clínicas psicológica e psiquiátrica.

\section{A invenção da doença mental}

Ao construir seus critérios diagnósticos, a clínica psiquiátrica encontrará dificuldades em apoiar-se na fisiologia, como a clínica médica geral. Se na medicina geral, o apoio na fisiologia não a impede de se circuscrever no campo dos valores, uma vez que se trata de uma tentativa de restauração de um bem - a saúde; no campo da saúde mental, o caráter moral da nosografia é fundamental. Lanteri-Laura (1994, p. 14) caracteriza bem o marcante aspecto moral relacionado às doenças mentais em comparação com as demais doenças. Segundo ele, ao tomarmos como objeto uma doença como a tuberculose, mesmo que valores sociais estejam a ela associados, o conhecimento a respeito dela pode se desvincular da opinião cultural, descrevendo, por exemplo, as lesões tecitológicas que a determinam. A partir daí, uma história do saber médico sobre a tuberculose pode se separar de uma história do pensamento popular sobre essa doença. $\mathrm{O}$ mesmo não acontece com as doenças mentais, pois é a doxa que 
determina o campo de fenômenos de que a episteme irá se ocupar. Ou seja, a patologia mental está intrinsecamente relacionada a um conjunto de valores sociais que a julga, mais que isso, que a delimita.

Traçar a história da doença mental é traçar de algum modo a história dos valores que a delimitaram. A clássica obra de Foucault (2005a), História da Loucura, apresenta a história das idéias que justificaram mudanças na concepção de loucura e as conseqüências dessas idéias para o encaminhamento dado ao que fosse classificado como loucura. Para Foucault (2005a), as concepções de loucura vão mudando de acordo com as mudanças ocorridas nos critérios de racionalidade que a determinam e estes variam conforme o discurso no poder. É assim que a loucura deixa de ser concebida como possessão demoníaca e passa a ser considerada objeto das ciências, de que se ocuparão a medicina e a psicologia. Caberá às ciências da loucura, em nome da verdade e do bem que representam, legislar sobre a vida, quer seja punindo, educando, afastando da sociedade ou medicando. No entanto, ao se tornar objeto do saber médico, ocorre com a loucura o que Foucault (2005a) chamou de naturalização, ou seja, progressivamente o saber sobre a loucura se esquece de seu ponto de partida moral e se vê dispensado de repensar o poder que exerce.

Segundo Foucault (2005a), para que a loucura seja claramente tomada como objeto médico, é necessário que ela seja compreendida como evento natural, o que acontece no final do século XVIII, com o surgimento da medicina anatomicamente baseada. A loucura se insere, então, no mundo das doenças "cuja verdade se enuncia por si mesma nos fenômenos observáveis" (Foucault, 2005a, p. 190). A nascente medicina da doença mental se organiza à semelhança da botânica, estabelecendo um jardim de espécies cuidadosamente classificadas a partir da observação atenta. A doença se torna, como Foucault (2003) descreve no livro $O$ Nascimento da Clínica, a verdade natural revelada pelo médico, ou melhor, pelo fisiologista.

Por sua vez, o surgimento da psicologia só é possível quando uma nova organização da loucura é realizada, não só considerando-a como doença, mas como doença mental, separando duas possibilidades de definição: afeção orgânica e afecção moral. No entanto, para Foucault (2001, 2005a,b), independente da aposta etiológica, a prática da saúde mental se constrói sob o ideal da normalização.

\section{A busca da normalidade}

Entendendo normalidade no sentido definido por Canguilhem, vale lembrar, como estabelecimento de um valor, Foucault (2001) se propõe a contar a história do conceito de anormalidade para a psiquiatria. Ele começa sua análise do anormal através dos exames psiquiátricos nos processos judiciários. Segundo Foucault (2001), a psiquiatria se volta para o campo da anormalidade a partir da prática jurídica do exame psiquiátrico. No exame jurídico, o psiquiatra é convocado a julgar a anormalidade do réu de forma que não será julgado apenas o crime, mas a anormalidade considerada causa dele. Serão tomadas como anormais irregularidades em relação a amplo tipo de regras que podem ser fisiológicas, psicológicas ou morais. Além disso, a anormalidade não dirá respeito a oposições rígidas, mas a gradações do normal ao anormal, de forma a possibilitar um enquadre ainda mais amplo. A psiquiatria, permanecendo fiel ao ideal médico, terá como objetivo a terapêutica. $\mathrm{O}$ anormal será, então, objeto de um saber de adaptação, de correção, de reinserção nas regras que transgrediu. Em decorrência disso, o punir passa a relacionar-se ao curar, expressão do que Foucault (2005b) chamou de poder de normalização, manifestação exemplar de uma sociedade disciplinar.

A sociedade disciplinar é caracterizada por Foucault (2005b) como aquela que exerce seu poder de maneira diluída, através de instrumentos simples de controle: o olhar hierárquico, que estabelece o grau de adequação individual ao esperado, classificando a anormalidade; o objetivo normalizador, que se utiliza de técnicas para a readaptação do indivíduo e uma prática de exame, com vias a fiscalizar o processo de normalização.

De acordo com Foucault (2001), nas primeiras aparições da figura do anormal no exame psiquiátrico dos crimes, merece destaque a sua natureza contranatural, expressa em seu caráter antropófago e incestuoso trata-se de um monstro, de uma caricatura de anormalidade. Entretanto, a partir do fim do século XIX, a psiquiatria começa a se interessar pelas minúcias do cotidiano, lançando seu olhar a tudo que possa ser julgado expressão de anormalidade. Dessa nova conformação da psiquiatria, ocorrida a partir do final do século XIX, decorre sua inserção no campo da anormalidade de tudo aquilo que biológica ou socialmente possa ser considerado anormal. Por seu caráter de vigia da ordem social, tomará a norma como regra de conduta, por sua ancoragem na medicina somática, tomará o normal como regularidade funcional. Ora, se 
o campo da psiquiatria passa a ser a anormalidade, obviamente se entenderá por cura a readaptação às normas.

A partir de então, ao médico - mestre da loucura e protetor da ordem social - caberia o poder, em maior ou menor grau de acordo com a época e o contexto, sobre a vida do doente. $\mathrm{O}$ ato de libertação dos grilhões, realizado por Pinel e imortalizado pela história da psiquiatria, instaura um outro tipo de poder. Não se trata do poder localizado e violento do soberano poder de prender e torturar, mas de um poder diluído de assujeitamento e disciplina - poder de moldar.

\section{Do poder da norma}

A normalização do indivíduo não será, entretanto, privilégio da psiquiatria. Segundo Foucault (2001, 2005b), a partir do final do século XVIII, as relações de poder em nossa sociedade são profundamente marcadas pela vigilância, pelo controle e pela correção. Foucault (2005b) usa como alegoria da sociedade disciplinar, o panopticon, elaborado por Bentham no final do século XVIII.

O panopticon é um edifício em forma de anel, no meio do qual há um pátio com uma torre no centro com um vigilante, encarregado de vigiar celas (educativas, punitivas, hospitalares) que se localizam no anel. O espaço deve ser projetado de tal maneira que tudo dentro da cela seja exposto ao olhar do vigilante, mas que não seja possível, da cela, distinguir o olhar do vigia, podendo-se supô-lo todo o tempo ${ }^{1}$. Para Foucault (2005b), essa arquitetura representa a utopia do poder pelo controle, por isso, ele caracteriza a sociedade disciplinar como panóptica. Embora as organizações panópticas, mesmo tendo existido, possam parecer caricaturais, seu ideal apenas se adaptou a novas formas espaciais, permanecendo a expectativa do olhar e do controle. Nessa estrutura, é preciso banir ou dominar o acaso. Tudo pode e deve ser calculado, ideal da servidão integral da natureza ao útil, idealização de um mundo perfeitamente organizável segundo a lógica do útil, sem restos. Deve-se, para tal, aprender a lógica das classes e distribuir cada coisa em seu lugar.

Uma instituição que funcione segundo a lógica panóptica não tem por objetivo excluir, mas fixar os indivíduos, controlando-os. O objetivo da sociedade disciplinar é adequar o indivíduo a uma norma, fixando-o a ela. A finalidade última desse mecanismo é fixar o indivíduo a uma norma, integrá-lo num esquema de normalização, mas ao mesmo tempo em que produz o normal, a disciplina produz o anormal. É possível situar o retardado mental como o indivíduo inadequado à disciplina escolar; o delinqüente, à disciplina policial; e o doente mental como um resíduo inassimilável ao mecanismo disciplinar de maneira geral. Para Foucault (2005b), a existência de resíduos inassimiláveis à disciplina é característica das sociedades disciplinares, pois estabelece seu ciclo de funcionamento: a existência do resíduo faz com que existam novos mecanismos disciplinares para englobá-lo, como por exemplo, a criação de escolas para débeis mentais. Constitui-se desse modo um perpétuo trabalho de disciplinarização dos anormais.

Mas, para Foucault (2002), o poder exercido pela saúde mental não pára aí. Além do poder disciplinar, expresso nas técnicas de controle dos indivíduos, exerce também um poder de regulamentação sobre as populações, sobre a vida em seu sentido mais amplo um biopoder. Ao passo que a tecnologia disciplinar se dirige aos corpos individuais para treiná-los, vigiá-los, usá-los e até mesmo puni-los, enquadrando-os segundo o formato do homem normal; a tecnologia do biopoder se dirige aos homens como uma massa global, afetados por processos próprios à vida, como nascimento, morte e doença. $\mathrm{O}$ biopoder se faz em direção não do homem-corpo, mas do homem-espécie (Foucault, 2002, p. 289).

É quando o olhar do estado se lança sobre as taxas de natalidade e mortalidade, sobre os índices de longevidade, problemas para os quais a estatística será a ferramenta fundamental e as ciências humanas o operador ideal. $\mathrm{O}$ poder soberano fazia morrer e deixava viver. O biopoder faz viver e deixa morrer. É um direito de intervir para fazer viver. Direito de intervir no "como da vida". Poder que se expressa claramente a partir do momento em que intervém para aumentar a vida, para controlar seus acidentes, suas eventualidades, para garantir que a vida se expresse apenas, ou ao menos preferencialmente, do modo adequado. Aqui o problema se torna como estabelecer esse adequado, problema que parece esquecido uma vez que, como vimos, esse nível de adequação, de normalidade, não é considerado como se fosse uma construção valorativa, mas como se fosse uma verdade da natureza revelada aos olhos atentos dos observadores especializados. $\mathrm{Na}$ verdade, trata-se de uma crença no discurso das coisas. A aposta que fundamenta esse tipo de concepção é de que a natureza fala, devendo os especialistas em ouvi-la, traduzir a verdade de seus ditos a que todos devem se conformar. 
Em suma, no jogo das relações sociais de poder, Foucault destaca as tecnologias disciplinares, centralizadas no corpo individual, que pretendem tornar dócil e útil; e as tecnologias reguladoras, que destinam seus esforços ao aos efeitos de massa, que tentam controlar ou ao menos minimizar: tecnologia de treinamento e tecnologia previdenciária. $\mathrm{O}$ poder disciplinar e o poder de regulação, no entanto, não se excluem, ao contrário, se articulam. A medicina e as ciências humanas, enquanto defensoras da normalidade, inseremse nesse espaço de cruzamento dos poderes disciplinares e de regulação.

O controle exercido pelas disciplinas e pela biopolítica se exerce a partir da norma: "A norma é o que pode tanto se aplicar a um corpo que se quer disciplinar quanto a uma população que se quer regulamentar" (Foucault, 2002, p. 302). Normalizar parece ser um lema abertamente assumido por nossa sociedade. Afinal, é preciso padronizar as coisas para que elas possam melhor se adequar ao estatuto de mercadoria.

Nesse contexto, as terapêuticas do mental surgem como aposta na possibilidade de tratamento dos desvios (morais?) que se manifestam na dita doença mental. O campo das doenças mentais apresenta dois problemas diagnósticos: primeiro é preciso discriminar o doente do saudável e apenas posteriormente realizar um diagnóstico diferencial. Julgar a presença da doença mental é um processo fundamentalmente valorativo, pois parte da prescrição de um nível de normalidade de forma que não parece haver outra saída para a saúde mental senão a imposição do poder da norma que representa ${ }^{2}$.

\section{0 círculo do poder}

Para Foucault (2002), não podemos, senão utopicamente, pensar a loucura de outro modo senão como produto de relações de poder que o conhecimento engendra. Mas isso implicaria, necessariamente, que o papel da saúde mental seria o de defesa da normalidade social? Nesse caso, ao mesmo tempo em que defenderia uma norma socialmente valorizada a saúde mental agiria como criadora dessas normas.

Essa circularidade do pensamento das ciências psicológicas é apontada por Foucault (2000). Ele define a psicologia como aposta num tratamento possível de desvios morais que se manifestam na loucura. Tratamento que encarna a verdade de uma cura e que conduz à moral, ao Bem: "A psicologia é somente uma fina película na superfície do mundo ético no qual o homem moderno busca sua verdade" (Foucault, 2000, p. 85). A psicologia acaba por se inserir num raciocínio circular com seu objeto - a loucura - ao mesmo tempo criando-a e tentando eliminá-la.

Retomemos que a doença psíquica é instituída a partir de determinado estabelecimento de valores, e, portanto, apresenta um caráter fundamentalmente moral. Podemos dizer que ela é o nome dado a um suposto desvio em relação a um ideal de saúde. Ideal que aponta para um bem ou felicidade que é possível alcançar, mais que isso, que todos devem alcançar. Bem para o qual as ciências psicológicas conhecem o caminho. Entretanto, apesar dos esforços terapêuticos, um mal-estar parece persistir, e a loucura ou a doença mental, como preferimos nomear atualmente, escapa insistentemente às tentativas terapêuticas de eliminála. Para Foucault (2002), a loucura como conhecemos nos nossos dias pode desaparecer, o que não cessará de se apresentar é a contradição humana que ela apresenta:

Os progressos da medicina poderão, de fato, fazer desaparecer a doença mental assim como a lepra e a tuberculose; mas uma coisa permanecerá: a relação do homem com seus fantasmas, com seu impossivel, com sua dor sem corpo, com sua carcaça da noite; uma vez o patológico posto fora de circuito, a sombria pertença do homem à loucura será a memória sem idade de um mal apagado em sua forma de doença, mas obstinando-se como desgraça. Para dizer a verdade, essa idéia supõe inalterável o que, sem dúvida, é o mais precário, muito mais precário do que as constâncias do patológico; a relação de uma cultura com aquilo mesmo que ela exclui, e mais precisamente a relação da nossa com essa verdade de si mesma, longínqua e inversa, que ela descobre e recobre na loucura. (Foucault, 2002, pp. 211-212)

A filosofia ocidental, se a tomarmos em termos de projeto, aponta sempre para um bem que é possível alcançar, um bem capaz de trazer a felicidade desejada por todos. A psicologia só se torna possível como representante desse ideal, como tentativa de conduzir a alma humana ao bem, diluído na equivalência de valores do mundo moderno (Julien, 1996, pp. 25-31).

Para propor uma cura, tal como faz a psicoterapia, é preciso estar orientado por um bem, por um ideal que responda o que é a saúde. O risco é o trabalhador da saúde mental se assemelhar ao da polícia na vigia e controle dos desvios expressos na doença mental. Canguilhem (1999) fez um célebre comentário sobre a psicologia, ironicamente se referindo a localização 
geográfica do instituto de psicologia, dizendo que ao sair da Sorbonne, os psicólogos poderiam subir ou descer a ladeira, se subissem, encontrariam o Panthéon (a filosofia), se descessem, encontrariam a Chefatura de Polícia (o controle social). Ele destaca com essa alegoria o caráter moral da psicologia ao situar-se como responsável pela norma mental e aponta duas possibilidades de encaminhamento: refletir sobre a moral que a orienta e nesse sentido aproximar-se da filosofia, ou adotar uma moral como axioma e cuidar para que seja obedecida, aproximando-se da polícia. Com esta alegoria, Canguilhem encerra o artigo onde critica a psicologia por sua dificuldade em situar-se quer como ciência, quer como medicina, quer como ética. A crítica de Canguilhem situa a psicologia como "medicina sem controle, ética sem exigências e filosofia sem rigor" (Canguilhem, 1999, p. 12). Diante de tão ácida crítica, como pensar uma condução para o campo do que nomeamos saúde mental?

\section{A contabilidade do mental}

Os mecanismos normalizadores realizam uma investigação detalhada dos mínimos sinais, estabelecendo uma contagem em que se baseará a norma e, por conseguinte, a anormalidade. Para chegar a essa verdade que a norma revela é preciso saber contar, não uma conta qualquer: é preciso saber produzir o objeto a ser contado, do exato modo em que o discurso sobre ele (ou dele, se usarmos a lógica da fala das coisas) possa ser reconhecido como válido pelos próprios mecanismos de normalização.

O poder de normalização requer, de acordo com Foucault (2005b), não apenas mecanismos que o instale e mantenha, mas também mecanismos que verifiquem sua eficácia, o que ele nomeou como prática de exame. Milner (2005), por ocasião da tentativa institucional de controle da prática psicológica na França, tece algumas considerações a respeito das práticas de exame em nossa época, revelando-as, na esteira de Foucault, como mecanismos de normalização. Para esse autor, os mecanismos de exame, que vemos figurar atualmente sob o nome genérico de avaliação, não se dirigem ao nível conceitual, mas a uma prática mecânica de normalização. $\mathrm{O}$ avaliador não precisa conhecer o objeto avaliado, ele precisa apenas contálo, ouvir a realidade que o objeto revela, configurada sob o padrão revelador de suas perguntas. O objetivo da avaliação é, pois, extrair normas e verificar a adequação a elas.

E o que pode ser avaliado? Tudo, já que a avaliação por si só não tem conteúdo, ela é apenas um mé- todo no qual os objetos devem se encaixar. A avaliação fornece uma forma que visa a transformar o singular no mais um de uma contagem. A avaliação conta e compara. Ao comparar, geralmente com um valor médio, ela estabelece uma falta, a qual os especialistas se esforçaram para sanar. O objetivo maior da avaliação é a domesticação universal (Milner, 2005, p. 12). Seu lema é avaliar em detalhes, tudo revelando. $O$ olhar do avaliador funciona, pois, sob o ideal de controle total, ideal panóptico. O avaliador se caracteriza pela especialidade de um olhar que consegue captar a verdade que as coisas revelam e traduzi-las, ele ouve a verdade das coisas através de seus métodos, e são elas que dizem a verdade, a qual, por fim, só resta obedecer: estamos diante de um governo das coisas. A avaliação seria, segundo o autor, apenas mais um episódio do governo das coisas. Uma vez revelada a verdade das coisas, verdade suposta sem sujeito, portanto incontestável, é preciso acomodar-se a ela: trata-se de uma clara pedagogia da aceitação.

Entretanto, o reino absoluto das coisas é a morte, pois a vida não é estática o bastante para se adequar à contagem. Para Foucault (2003), é a morte que permite à medicina tomar o homem como objeto de um olhar positivo, olhar "coisificante". Para que houvesse uma ciência do homem, este precisou ser constituído como objeto, e, como conseqüência, destituído de sua humanidade. É sobre esse homem, tornado objeto mensurável, que a avaliação atua. Por isso, a igualdade operada pela contabilidade do humano é absoluta (de fato, não de direito), tornando cada coisa mensurável e substituível. Só se pode contar o igual, mas não havendo diferença (igualdade absoluta), tudo é substituído. Governo das coisas, pois não há diferença e, portanto, não há soberania, trata-se de um poder que se gera e se mantém.

A circularidade do sistema avaliativo, sistema normalizador por excelência, torna difícil escapar das malhas de seu poder. A avaliação não tem conteúdo, ela é um molde que pode se encaixar a qualquer coisa, ou melhor, a tudo, já que tudo é promovido ao estatuto de coisa. Mas, astuto golpe de seu poder, se ela não tem conteúdo, ela não pode ser avaliada. Como não tem conteúdo, a avaliação não pode estabelecer seus próprios critérios. Ela os usa na medida em que interessa aquele que a solicita, num movimento de autogeração de valores. Assumir uma aparência médicocientífica, usando um vocabulário especializado, permite mascarar o caráter arbitrário dos critérios, convencendo que eles estão nas próprias coisas. Mas, na 
verdade, as coisas não falam: os porta-vozes das coisas são porta-vozes deles mesmos (Milner, 2005, p. 35). A avaliação concerne à coletividade, conferindo ao individual uma aparência, uma definição, uma tipologia, uma medida, uma marcação, apagando a singularidade. Portanto, o conteúdo avaliado não tem a menor importância: o que está em jogo é a sujeição a esses mecanismos de poder. Na lógica da avaliação permanece o que for melhor avaliável. Por isso, aquilo que não se encaixa nas avaliações e tratado com descrédito. Se pensarmos a partir de Foucault, podemos dizer que a avaliação permite ao indivíduo entrar no mecanismo de normalização, verificando qual o seu grau de normalidade e se precisa de correção especializada. Em decorrência disso, a avaliação tem horror à liberdade, já que ela só funciona com padrões: "A avaliação universal alça mão de tudo que existe para transformar em um vasto catálogo de coisas avaliáveis. A doutrina que a suporta não mobiliza nenhum pensamento; salvo um: a razão do mais forte" (Milner, 2005 , p. 17). Mas este poder se apresenta diluído no aceito fenômeno do governo das coisas, governo que, não esqueçamos, é aceito.

Se são as coisas que governam, através de uma verdade sem sujeito e incontestável, não parece restar outra saída senão conformar-se ao seu reinado. Várias especialidades são chamadas a dar testemunho desse governo das coisas, legitimando-o e fazendo valer seu poder de normalização, lugar que as práticas envolvidas no que chamamos saúde mental, podem ocupar com mestria. Em nossa época, tornou-se fato corriqueiro o tratamento com psiquiatras e psicólogos: se há saúde mental à disposição, deve-se consumi-la, pois é preciso entrar na lucrativa contabilidade das coisas.

\section{CONSIDERAÇÕES FINAIS}

Vivemos na sociedade da saúde, onde os mais diversos meios de obtê-la e mantê-la são oferecidos pelo mercado. Os progressos científicos e tecnológicos permitem ao homem tanto superação de doenças antes fatais, como maior longevidade. Os resultados das pesquisas, tomados numa perspectiva moralizante, são utilizados como parâmetros para orientar a vida humana, instituindo toda sorte de prescrições. Entretanto, a ciência, utilizada como fundamento de uma moral da saúde, não pode, pelo fato de prolongar a vida, dispensar o homem do confronto que a morte representa, possibilitando uma interrogação através da qual o sentido, o tipicamente humano, é construído.
É verdade que os psicotrópicos possibilitaram perspectivas novas para os doentes mentais, mas também é verdade que seu uso na nossa sociedade, especialmente devido ao lucro que representa, é há muito abusivo. Não parece distante o dia em que os modeladores de humor serão de consumo freqüente. O homem do futuro poderá acordar pela manhã (se é que dormir ainda será necessário) e decidir qual o temperamento mais útil para aquele dia, tomando para isso, a pílula adequada. Essa possibilidade, em si, não é preocupante. Assustador é pensar que o sujeito poderá estar apagado do projeto humano. Não importa se o humor possa ou não ser quimicamente controlado, desde que o homem não perca sua capacidade de se perguntar: desejo isso?

A revolução anátomo-patológica da medicina é marcada pela identidade entre lesão e doença, produzindo uma possibilidade de conceber objetivamente a doença. Porém, vimos com Canguilhem que uma concepção de doença é essencialmente qualitativa, pois parte de um julgamento que estabeleça o bem e o mal. A medicina toma a vida humana como valor máximo em relação ao qual orientar suas ações e a descrição fisiológica ou química como instrumento para avaliar a normalidade de uma apresentação corporal. A psiquiatria, por sua vez, encontra dificuldades em fundamentar seu conceito de doença num indicativo fisiológico ou químico. Em auxílio à dificuldade do saber psiquiátrico, a psicologia surge como tentativa de estabelecer critérios que fundamentem a classificação psicopatológica para além dos marcadores biológicos. Ambas as disciplinas, entretanto, se ocupam da promoção da saúde mental utilizando-se de uma mesma lógica organizativa que permite separar o doente do saudável através de um conjunto de critérios eleitos como adequados. No campo da saúde mental, o valor moral das noções de saúde e doença é ainda mais explícito. Uma reflexão sobre o que está implicado nos conceitos de saúde e doença para uma disciplina é fundamental para apontar a que valores ela atende. Por isso, "qualquer elaboração teórica que concerna às doenças mentais, parece exigir, para toda questão que se coloque, uma discussão prévia de feitio epistemológico" (Simanke, 2002, p. 33).

Para Canguilhem (1999), a psicologia exerce uma função normalizadora sem refletir sobre o fundo moral de sua prática. Para Foucault $(2000,2001,2002$, 2003, 2005a,b), a saúde mental é um exemplo de mecanismo disciplinar que visa a controlar a vida dos indivíduos, de um lado, estabelecendo valores que separam o saudável do doente, de outro, legitimando 
os valores que ela própria estabeleceu, constituindo um círculo vicioso em que o poder da não-loucura sobre a loucura é mantido. Uma classificação do mental é, pois, estabelecida e com base nela, um tratamento é proposto. A classificação psicopatológica, realidade discursiva, tem sempre um toque de arbitrário. A escolha de um critério revela que uma hierarquia foi estabelecida, postulando um ponto superior aos demais. Assim, se tomo a adaptabilidade social como critério, posso construir um sistema classificatório com diferentes tipos de patologias e até mesmo com exceções, mas a escolha do critério é sempre uma decisão.

Um julgamento moral está, pois, no cerne da classificação psicopatológica, uma vez que é preciso nessa lógica estabelecer um conjunto que em última instância, separe o bem do mal. A discussão ética deve, pois, ser constantemente levantada pelos profissionais de saúde mental, num exercício criativo que permita às práticas terapêuticas a aceitação da diferença para além dos ideais normalizadores. Isso significa que as terapêuticas psi devem se manter num lugar sempre aberto a reavaliações, em constante movimento, trazendo para sua estrutura, a reflexão sobre os impasses éticos humanos.

\section{REFERÊNCIAS}

Canguilhem, G. (1999). Que é a psicologia? (O. F. Gabbi Jr., Trad.). Impulso, 11(26), 11-26.
Canguilhem, G. (2002). O normal e o patológico (5 ed.) (M. T. R. Barrocas \& L. C. F. B. Leite, Trads.). Rio de Janeiro: Forense.

Foucault, M. (2000). Doença mental e psicologia (6 ${ }^{\mathrm{a}}$ ed.) (L. R. Shalders, Trad.). Rio de Janeiro: Tempo Brasileiro.

Focault, M. (2001). Os anormais - Cursos do Collège de France 1974-75 (E. Brandão, Trad). São Paulo: Martins Fontes.

Foucault, M. (2002). A loucura, a ausência de obra. Em M. Foucault, Ditos e escritos I. Problematização do sujeito: Psicologia, psiquiatria e psicanálise (pp. 210-219), (V. L. A. Ribeiro, Trad.). Rio de Janeiro: Forense.

Foucault, M. (2003). O nascimento da clínica (R. Machado, Trad.) $\left(5^{\mathrm{a}}\right.$ ed.). Rio de Janeiro: Forense.

Foucault, M. (2005a). História da loucura na idade clássica ( $8^{\mathrm{a}}$ ed.) (J. T. Coelho Neto, Trad.). São Paulo: Perspectiva.

Foucault, M. (2005b). Vigiar e punir: Nascimento da prisão (R. Ramalhete, Trad.). Petrópolis: Vozes.

Julien, P. (1996). O estranho gozo do próximo (V. Ribeiro, Trad.). Rio de Janeiro: Jorge Zahar.

Lanteri-Laura, G. (1994). Leitura das perversões: História de sua apropriação médica (V. Ribeiro, Trad.). Rio de Janeiro: Jorge Zahar.

Milner, J.-C. (2005). La politique des choses. Paris: Navarin.

Pessoa, F. (1976). O eu profundo e outros eus. Rio de Janeiro: Manancial.

Simanke, R. (2002). Metapsicologia lacaniana: Os anos de formação. São Paulo: Discurso Editorial; Curitiba: Editora UFPR.

Recebido: $19 / 07 / 2007$

Última revisão: 05/11/2007 Aceite final: 18/12/2007

\section{Notas:}

${ }^{1}$ Uma alusão aos shows televisivos como o Big Brother não deixa de ser oportuna.

${ }^{2}$ De acordo com a OMS, a saúde não se definiria negativamente pela ausência de doença, mas positivamente, através de um estado de completo bem estar físico, mental e social. Essa definição, bastante abstrata, permitiria pensar que qualquer abalo nesse suposto bemestar, poderia ser classificado como doença. Isso leva a pensar que o indivíduo saudável seria bem adaptado física, mental e socialmente, ou seja, dentro das normas.

\section{Sobre a autora:}

Magali Milene Silva: Mestre em Psicologia pela UFMG.

Endereço para correspondência: Rua Flor de Fogo, 65 - apto 202 - Bloco 05 - Liberdade - 31270-217 Belo Horizonte/MG - Endereço eletrônico: magalimilene@hotmail.com. 